ЧеРНЕЦКАЯ Н. И., ЗЫРЯНОВА И. А., КЕДЯРОва Е. А., МОНЖИЕВСКАЯ В. В., УВАРОвА М. Ю.

ЛИЧНОСТНЫЕ ОСОБЕННОСТИ ЖЕНЩИН С НЕГАТИВНЫМИ УСТАНОВКАМИ В СФЕРЕ СЕКСА

РосСиЙский психологИчЕский жУРнАл, 2020, Т. 17, № 2, 58-72. doi: 10.21702/rpj.2020.2.4

ОБЩАЯ ПСИХОЛОГИЯ, ПСИхОЛОГИЯ ЛИЧНОСтИ, ИСтОРИя ПСИхОЛОГИИ

УДК 159.9.072.43 doi: 10.21702/rpj.2020.2.4

Оригинальная научная статья

\title{
Личностные особенности женщин с негативными установками в сфере секса
}

\author{
Надежда И. Чернецкая ${ }^{1 *}$, Инна А. Зырянова², Елена А. Кедярова', Вера В. Монжиевская", \\ Маргарита Ю. Уварова ${ }^{1}$ \\ ${ }^{1}$ Иркутский государственный университет, г. Иркутск, Российская Федерация \\ 2 ООО «АБАП ТИМ», г. Иркутск, Российская Федерация \\ * E-mail: cherna@yandex.ru \\ ORCID ID: https://orcid.org/0000-0001-7082-5444, https://orcid.org/0000-0003-0028-5862, \\ https://orcid.org/0000-0001-9124-9503, https://orcid.org//0000-0001-8437-0225, \\ https://orcid.org/0000-0002-1597-9093
}

\begin{abstract}
Аннотация
Ввеление. Проблема изучения личностных особенностей женщин, способствующих их успешной самореализации как субъекта сексуального поведения, сеголня особенно актуальна. В русле тенАенции к снижению половой сегрегации женщины Аолжны быть Аовольны смягчением норм, ограничивающих проявление их сексуальности, однако на практике наблюдается рост числа женщин, обращающихся по поводу сексуальных проблем. Новизна преАставленного исслеАования состоит в фокусировании исслеАовательского интереса непосредственно на выборке женщин с негативными сексуальными установками с целью изучения у них специфических личностных особенностей.

Методы. В исследовании приняли участие 152 женщины (клиентки кризисных и консультационных центров г. Иркутска). Отношение женщин к сексу изучалось с помощью «Опросника установок к сексу» Г. Айзенка. А^я составления ^ичностных проорилей женщин с разными установками в сорере секса использовался опросник Р. Кеттел^а (форма С). Аостоверность различий оценивалась с помощью критерия $\varphi^{*}$ Фишера.

Результаты. Вылелено шесть групп женщин, имеющих позитивное и негативное отношение к различным аспектам сексуальной сореры, у 15,38\% испытуемых выявлено отвращение к сексу. Выявлены Аостоверные отличия женщин с негативными и позитивными установками к фризическому сексуальному контакту по фрактору «фремининность-маскулинносты.. Аанный орактор отвечает за выраженность в поведении женщины традиционного женского сексуального поведения, следование жестким моральным нормам, что согласуется с низкими бал^ами по шкалам теста Айзенка («Аозволенносты), «обезличенный секс», «сексуальная возбуАимость» и «сексуальное мибиАо»).

Обсужаение результатов. Выявлено, что среди женщин с негативными установками в сорере секса преоблалают тралиционные фремининные взглялы на сексуальность, сохранение брачных уз, а также нетерпимое отношение ко всему постылному. В ^ичностных проори^ях женщин с негативными установками в сорере секса преобладают ригиАность мышления, высокая нормативность пове Аения, полчиненность, застенчивость, сАержанность в проявлении эмоций, погАощенность внутренними и^^Юзиями.
\end{abstract}


ЧеРНЕЦКАЯ Н. И., ЗЫРЯНОВА И. А., КЕДЯРОвА Е. А., МОНЖИЕВСКАЯ В. В., УВАРОВА М. Ю.

ЛИЧНОСТНЫЕ ОСОБЕННОСТИ ЖЕНЩИН С НЕГАТИВНЫМИ УСТАНОВКАМИ В СФЕРЕ СЕКСА

РосСИЙСКИЙ пСИХОЛОГИЧЕСКИЙ ЖУРнАл, 2020, Т. 17, № 2, 58-72. doi: 10.21702/rpj.2020.2.4

ОБЩАЯ ПСИХОЛОГИЯ, ПСИХОЛОГИЯ ЛИЧНОСТИ, ИСТОРИЯ ПСИХОЛОГИИ

\section{КАючевые слова}

установка, сексуальность, секс, сексуальное поведение, женская сексуальность, фремининность, сексуальные установки, отношение к сексу, генАерная инАивиАуальность, нормативность повеАения

\section{Основные положения}

$\checkmark$ среди женщин с негативными установками в сорере секса преоблалают традиционные фремининные взгляды на сексуальное поведение, стремление к установлению ^ичных отношений межАу партнерами, сохранению брачных уз, нетерпимое отношение ко всему «аморальному» и «ПОстыАНОмуџ);

> как прави^о, женщины с негативными установками в сорере секса имеют низкую сексуальную чувствительность И возбуАимость;

$\checkmark$ Аля женщин с крайне негативным отношением к сексу характерны повышенная чувствительность, скАонность К РОМантизму, беспокойство, ранимость, скАОНность К Аепрессиям,

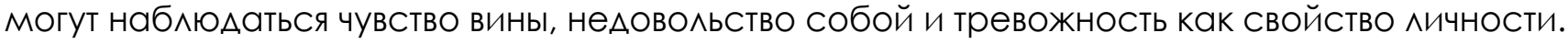

\section{Для цитирования}

Чернецкая, Н. И., Зырянова, И. А., Кедярова, Е. А., Монжиевская, В. В. и Уварова, М. Ю. (2020). Личностные особенности женщин с негативными установками в сфере секса. Российский психологический журнал, 17(2), 58-72. doi: 10.21702/rpj.2020.2.4

Дата получения рукописи: 30.03 .2020

Дата окончания рецензирования: 10.06 .2020

Дата принятия к публикации: 16.06 .2020

\section{Введение}

Проблема изучения личностных особенностей, способствующих успешной адаптации и самореализации женщины, в том числе и как субъекта сексуального поведения, приобретает сегодня особую актуальность. Глобальные изменения, произошедшие в обществе на протяжении XX в., затронули не только экономическую и политическую сферы, но и культуру, и, как следствие, отразились на самосознании женщин. Вопрос о гендерных различиях мужчин и женщин в настоящее время трансформировался в вопрос о гендерной индивидуальности, на что указывает, например, Ильин (2007). Peplau (2003), Голод (1996), Ellis (2010), Sathyanarana Rao \& Nagaraj (2015) пишут о том, что сексуальность также претерпела существенные изменения, и многие ее психологические «основы» сейчас изменились.

Ломка гендерных стереотипов ведет к трансформации брачно-семейных, партнерских отношений, затрагивает сексуальную сферу, что приводит к изменению отношения женщин к сексу (Чалова, 2015, 2016). В русле общей тенденции к снижению половой сегрегации, женщины, как кажется, должны быть довольны смягчением норм морали и культурных ценностей, ограничивающих проявление их сексуальности. Однако на практике наблюдается иная картина. Сексологии уверяют, что в настоящее время, параллельно с повышением уровня сексуальной культуры и информированности в вопросах секса, растет число женщин, обращающихся по поводу сексуальных проблем (Гусакова, 2010; Дерягин, н.д.; Дерягин, Сидоров и Соловьев, 2003; Bass, 2016; Кришталь, н. д.). С одной стороны, это говорит 
ЧеРНЕЦКАЯ Н. И., ЗЫРЯНОВА И. А., КЕДЯРОва Е. А., МОНЖИЕВСКАЯ В. В., УВАРОвА М. Ю.

ЛИЧНОСТНЫЕ ОСОБЕННОСТИ ЖЕНЩИН С НЕГАТИВНЫМИ УСТАНОВКАМИ В СФЕРЕ СЕКСА

РосСиЙскиЙ психологИЧЕСКИЙ жУРнАл, 2020, Т. 17, № 2, 58-72. doi: 10.21702/rpj.2020.2.4

ОБЩАЯ ПСИХОЛОГИЯ, ПСИХОЛОГИЯ ЛИЧНОСТИ, ИСТОРИЯ ПСИХОЛОГИИ

о преодолении стеснения в обсуждении этой темы и повышении интереса к вопросам женской сексуальности, а с другой стороны указывает на более глубоко скрытые механизмы возникновения женских сексуальных проблем, нежели простое отсутствие информации относительно различных аспектов сексуальной жизни (Kinsey, Pomeroy, Martin, \& Gebhard, 1998; Чалова, 2015, 2016).

Для женщин, воспитываемых десятилетиями в атмосфере жестких гендерных стереотипов, транслирующих пассивную роль женщины, современные лозунги о равноправии женщин, в том числе в вопросах сексуального самоопределения, представляют некий вызов, т. к. требуют перестройки внутренних конструктов личности, в том числе сложившихся установок и отношения к сексу. Исследования по вопросам репродуктивных установок женщин, их отношения к материнству, к сохранению девственности, к сексуальной депривации проявляют двойственность данного вопроса и наличие внутриличностного конфликта, приводящего к трудностям адаптации женщин в современных условиях (Маркова, н.д.; Нашхоев и Ильина, 2000; Нохуров, 1988; Попова, 2006; Темкина, 2002; Renshaw, 2001). Amaro (1995), в частности, указывает на искажения в сексуальных установках современных женщин в контексте риска ВИЧ-заражения.

Geer \& Robertson (2005), Fisher, White, Byrne, \& Kelley (1988), а также испаноязычные исследователи García-Vega, Rico, \& Fernández (2017) убедительно показали, что сексуальные установки не только определяют поведение женщины в целом, но и формируют ее личностные качества.

Роль сексуальных установок в сексуальном фантазировании показана Hsu, Kling, Kessler, Knapke, Diefenbach, \& Elias (1994).

Rammsayer, Borter, \& Troche (2017), Petersen \& Hyde (2010), Meston \& Ahorld (2010) описали специфику сексуальных установок у женщин разных этнических групп с учетом фактора возраста и образования.

В целом наблюдается недостаток исследований, которые бы детально и комплексно рассматривали психологические особенности личности женщин с различными сексуальными установками. Это и определило цель настоящего исследования - изучить личностные особенности женщин с негативными установками в сфере секса.

В качестве основной гипотезы исследования выступило предположение о том, что женщины с негативными установками в сфере секса обладают специфическими личностными особенностями. В частности, предполагалось, что негативная сексуальная установка имеет позитивную связь с такими чертами личности, как робость, тревожность, замкнутость, высокая нормативность поведения, ригидность мышления, чувствительность, мечтательность.

\section{Методы}

В эмпирическом исследовании принимали участие 152 женщины (клиентки кризисных и консультационных центров г. Иркутска). Выборка была сформирована методом стратометрического отбора. Испытуемые женщины подбирались с учетом необходимого баланса по уровню образования, социального статуса и семейного положения: балансировка стратометрических слоев достигалась на уровне 50-50\% по уровню образования, на уровне 30-40\% по возрасту, на уровне 40-60 \% по уровню доходов, на уровне 50-50 \% по семейному статусу. За счет стратометрического подхода к формированию выборки удалось добиться относительной независимости полученных в дальнейшем результатов от формальных характеристик испытуемых женщин. Средний возраст испытуемых женщин - 42 года. 
ЧеРНЕЦКАЯ Н. И., ЗЫРЯНОВА И. А., КЕДЯРОвА Е. А., МОНЖИЕВСКАЯ В. В., УВАРОВА М. Ю. ЛИЧНОСТНЫЕ ОСОБЕННОСТИ ЖЕНЩИН С НЕГАТИВНЫМИ УСТАНОВКАМИ В СФЕРЕ СЕКСА

РосСИЙСКИЙ пСИХОЛОГИЧЕСКИЙ ЖУРнАл, 2020, Т. 17, № 2, 58-72. doi: 10.21702/rpj.2020.2.4

ОБЩАЯ ПСИХОЛОГИЯ, ПСИХОЛОГИЯ ЛИЧНОСТИ, ИСТОРИЯ ПСИХОЛОГИИ

В исследовании были использованы следующие методы психологической диагностики: тестовая методика «Опросник установок к сексу» Г. Айзенка и адаптированный вариант многофакторного личностного опросника Р. Кеттелла (форма С) (Айзенк и Вильсон, 2000; Рукавишников и Соколова, 2002).

Отношение женщин к сексу изучалось с помощью «Опросника установок к сексу», позволяющего наряду с исследованием отношения к сексу выявить прогноз удовлетворенности браком, отклонений в сексуальном поведении, проводить диагностику фемининности/маскулинности.

В опроснике Г. Айзенка нет шкалы, позволяющей напрямую оценить установку к сфере секса: анализ установки производится на основе обобщения значений шкал «дозволенность», «сексуальная возбудимость», «порнография», «обезличенный секс», «физический секс», «сексуальная застенчивость», «целомудрие» и «отвращение к сексу», позволяющих выявить установки испытуемых к различным аспектам сексуальной сферы. Это вполне оправдано, т. к. сексуальная установка - не только готовность к сексуальному поведению ради удовлетворения физиологической потребности, а сложный социально-психологический механизм, состоящий из комплекса поведенческих актов, установок, суждений, оценок и позиций личности. Кроме того, на формирование сексуальной установки оказывают воздействие не только биологические, но и средовые факторы: психологические, социальные, экономические, культурные, этические, правовые, исторические, религиозные и духовные, которые и находят свое отражение в установках женщин к различным аспектам сексуальной сферы, выявляемых опросником.

Ключи для каждой из шкал опросника установок к сексу содержат значения, позволяющие разделить выборку на группы испытуемых, имеющих четко определенное позитивное и негативное отношение к различным аспектам сексуальной сферы, и испытуемых, чей полюс в отношении к сексу ярко не выражен. В связи с этим, на первом этапе исследования мы выявили позитивное и негативное отношение женщин к сексу по результатам шкал «порнография», «физический секс» и «отвращение к сексу». Значения показателей по приведенным шкалам распределяются по противоположным полюсам, вплоть до максимального значения, что позволило нам выделить женщин с ярко выраженным позитивным и негативным отношением к исследуемым в указанных шкалах аспектам сексуальной сферы.

По результатам шкал «дозволенность», «сексуальная возбудимость», «обезличенный секс», «сексуальная застенчивость», «целомудрие» данные лежат в пределах низких и средних значений, что не представляет интереса для нашего исследования.

Достоверность различий оценивалась с помощью критерия $\varphi^{*}$ Фишера.

\section{Результаты}

На основании вышеописанного нами выделено шесть групп женщин, имеющих позитивное и негативное отношение к различным аспектам сексуальной сферы: порнографии, реальному половому контакту (шкала «физический секс») и сексуальности (шкала «сексуальное отвращение»).

В первую группу были включены испытуемые, набравшие от 6 до 8 баллов по шкале «порнография» опросника Айзенка - это женщины с ярко выраженным положительным отношением к порнографии, т. е. получению удовольствия от рисунков или фотографий, изображающих сексуальные сюжеты, или словесного описания сексуальных сцен, обычно в максимально откровенной форме. Женщины первой группы имеют высокий показатель по шкале «сексуальное 
ЧеРНЕЦКАЯ Н. И., ЗЫРЯНОВА И. А., КЕДЯРОва Е. А., МОНЖИЕВСКАЯ В. В., УВАРОвА М. Ю.

ЛИЧНОСТНЫЕ ОСОБЕННОСТИ ЖЕНЩИН С НЕГАТИВНЫМИ УСТАНОВКАМИ В СФЕРЕ СЕКСА

РосСиЙский психологИчЕский жУРнАл, 2020, Т. 17, № 2, 58-72. doi: 10.21702/rpj.2020.2.4

ОБЩАЯ ПСИХОЛОГИЯ, ПСИхОЛОГИЯ лИЧнОстИ, ИСТОРИя ПСИхОЛОГИИ

либидо» ( 21 балл) и средние значения по шкале «фемининность - маскулинность» ( 26 баллов).

Во вторую группу включены испытуемые, набравшие от 0 до 3 баллов по шкале порнография - это женщины с ярко выраженным негативным, неодобрительным отношением к порнографии. Для них также характерны низкие значения по шкалам «дозволенность», «обезличенный секс» и «сексуальное либидо». Значения по шкале «фемининность - маскулинность» лежат в пределах низких значений, что свидетельствует о выраженности фемининных качеств для данной группы женщин.

Испытуемые, набравшие от 3 до 6 баллов по шкале «порнография», исключены нами из исследования, т. к. их предпочтения ярко не выражены. В результате выборка разделилась на три равномерные части: у 32,69 \% испытуемых выявлена позитивная установка к порнографии, у 34,62 \% испытуемых выявлена негативная установка к порнографии, и у 32,69 \% испытуемых выявлена промежуточная позиция в отношении к порнографии (рис. 1).

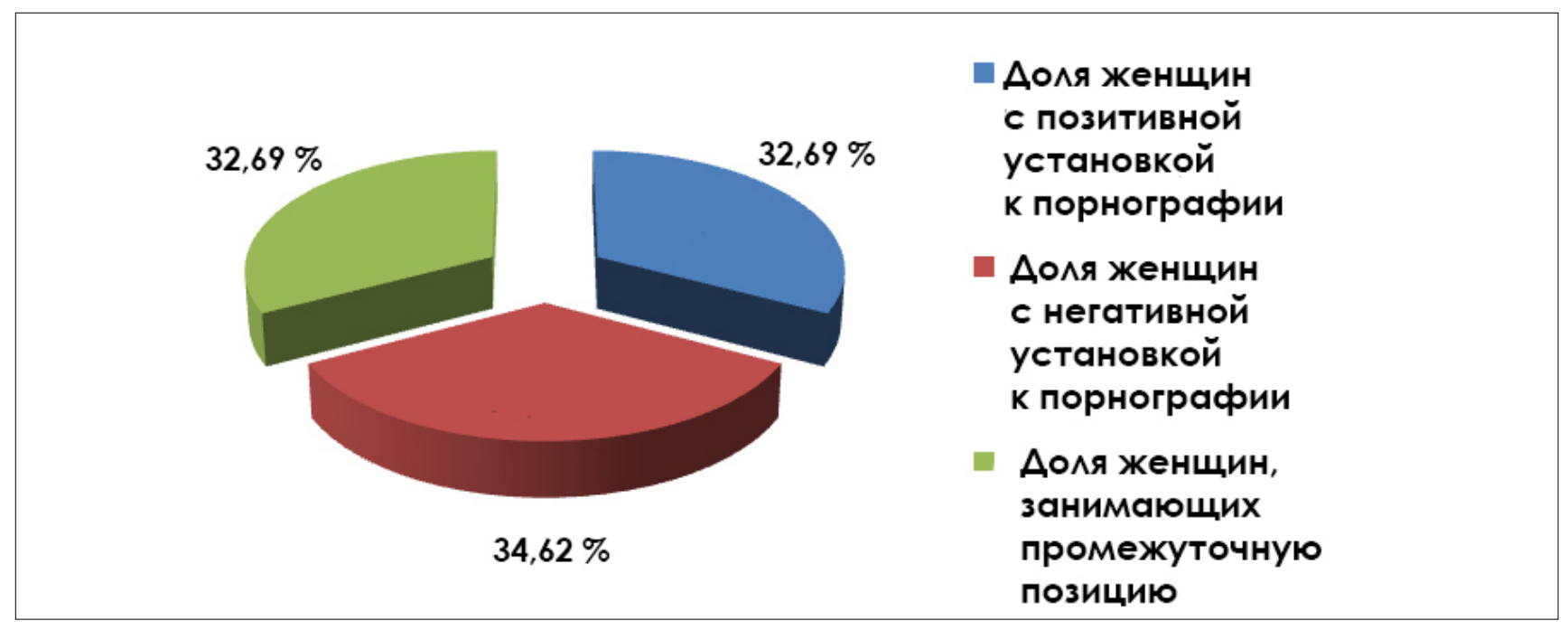

Рисунок 1. Соотношение численности женщин с разным полюсом установок к порнографии в выборке

В третью группу нами были включены набравшие от 6,5 баллов и выше по шкале «физический секс»-это женщины с ярко выраженным активным стремлением к реальному половому контакту; секс ставится превыше всего, и самому половому акту уделяется особое внимание за счет других сторон любовных отношений.

В четвертую группу вошли испытуемые, набравшие 3 балла и меньше по шкале «физический секс» - это женщины, избегающие реальных половых контактов, для них более предпочтительно духовное общение. Испытуемые, набравшие от 3 до 6,5 баллов по шкале «физический секс», исключены нами из исследования т. к. их предпочтения ярко не выражены.

Таким образом, мы выявили, что у 25 \% испытуемых женщин наблюдаются ярко выраженная позитивная установка к сексу и стремление к физическому контакту, у 17,31\% испытуемых выявлена крайне негативная установка на физический контакт, и у 57,69\% испытуемых выявлена промежуточная позиция в отношении к физическому сексуальному контакту (рис. 2).

В пятую группу мы включили набравших от 4,5 баллов и выше по шкале «сексуальное 
отвращение» - эти женщины с отвращением реагируют на некоторые виды секса, даже занимаясь им со своим постоянным партнером.

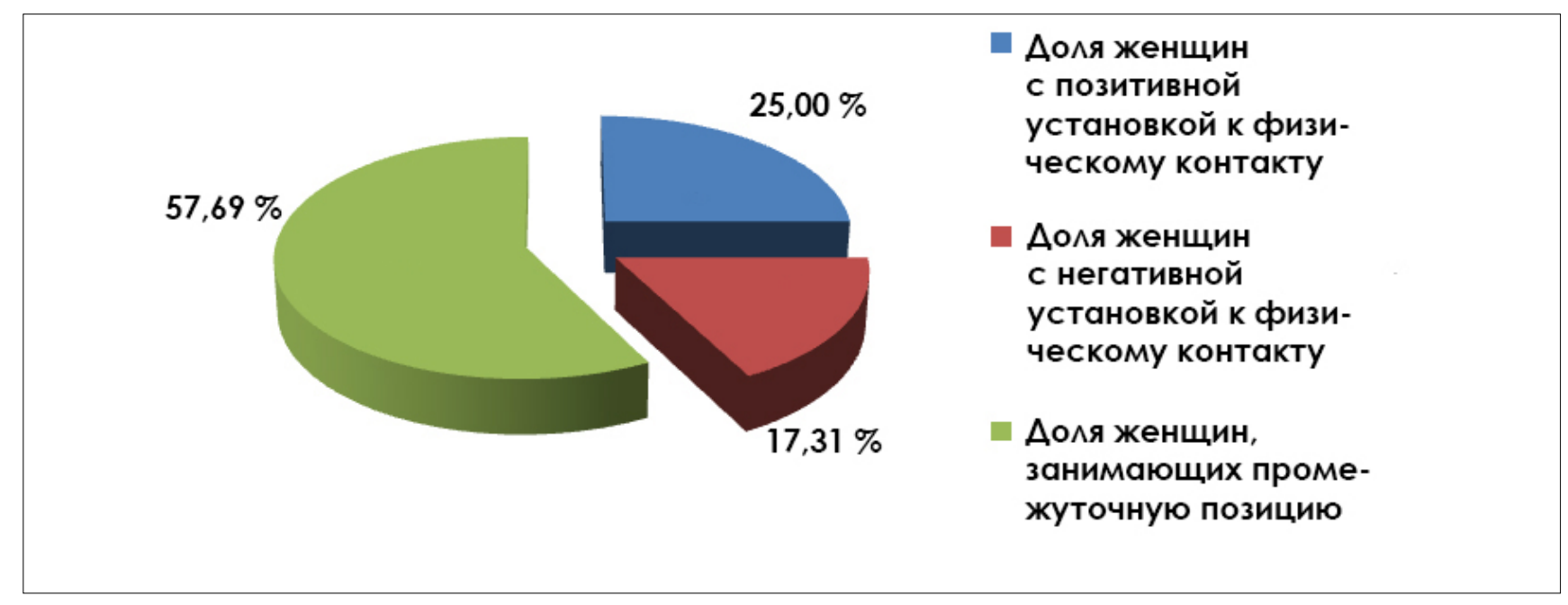

Рисунок 2. Соотношение численности женщин с разным полюсом установок к оризическому сексуальному контакту в выборке

Шестую группу составили испытуемые, набравшие 2 балла и ниже по шкале «сексуальное отвращение».

В результате тестирования нами выявлено, что доля женщин с позитивной установкой к проявлению сексуальности составляет 26,92 \%, у 15,38 \% испытуемых выявлено отвращение к сексу, у 57,69\% испытуемых выявлена промежуточная позиция к проявлению сексуальности (рис. 3).

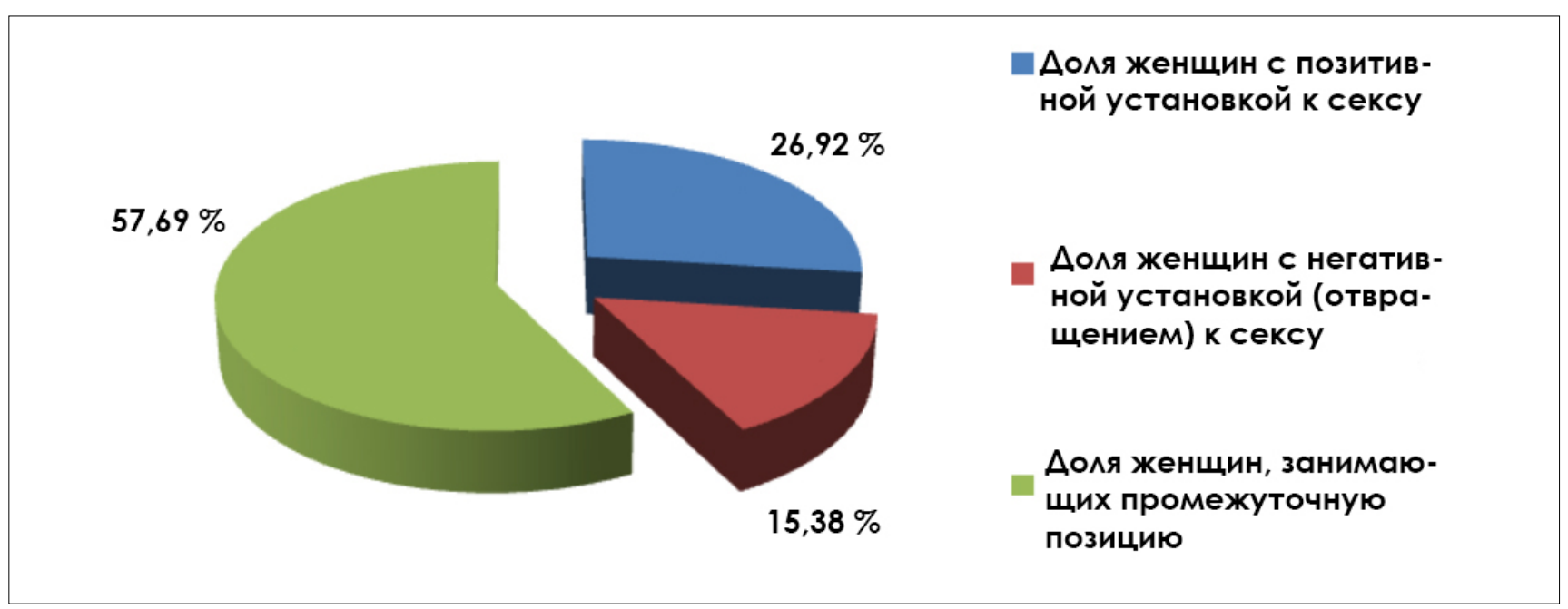

Рисунок 3. Соотношение численности женщин с разным полюсом установок к проявлению сексуальности в выборке 
ЧеРНЕЦКАЯ Н. И., ЗЫРЯНОВА И. А., КЕДЯРОва Е. А., МОНЖИЕВСКАЯ В. В., УВАРОвА М. Ю.

ЛИЧНОСТНЫЕ ОСОБЕННОСТИ ЖЕНЩИН С НЕГАТИВНЫМИ УСТАНОВКАМИ В СФЕРЕ СЕКСА

РосСиЙский психологИчЕский жУРнАл, 2020, Т. 17, № 2, 58-72. doi: 10.21702/rpj.2020.2.4

ОБЩАЯ ПСИХОЛОГИЯ, ПСИХОЛОГИЯ ЛИЧНОСТИ, ИСТОРИЯ ПСИХОЛОГИИ

На следующем этапе исследования проведен анализ шестнадцати личностных черт женщин, которые вошли в шесть выделенных групп, и проанализирован дополнительный фактор самооценки: А - показатель уровня межличностной общительности; В - интеллект; С - эмоциональная неустойчивость / эмоциональная устойчивость; E - конформность/доминантность; F - сдержанность/экспрессивность; G - степень принятия моральных норм: сознательность/ беспринципность; H - застенчивость/смелость; I - чувственность/твердость; L- подозрительность/ доверчивость; М - мечтательность/практичность; N - прямолинейность/дипломатичность; O спокойствие/тревожность; Q1 - радикализм/консерватизм; Q2 - конформизм/нонконформизм; Q3 - низкий самоконтроль / высокий самоконтроль, сильная воля; Q4 -расслабленность / эмоциональная напряженность; MD - самооценка.

Анализ распределения факторов теста Кеттелла в усредненных профилях женщин с негативными и позитивными установками к порнографии (рис. 4) позволяет сделать вывод о большей выраженности в профилях женщин с негативным отношением к данному аспекту сексуальной сферы таких личностных черт, как открытость (A), эмоциональная стабильность $(\mathrm{C})$, сознательность $(\mathrm{G})$, радикализм (Q1), самостоятельность (Q2), застенчивость (H), покладистость (L), в отличие от женщин, одобряющих порнографию. Наблюдаются также более низкие значения по шкале интеллекта (B) и более высокая самооценка (MD), а с учетом данных по тесту Айзенка предполагается соответствие фемининному поведению женщины в вопросах секса. Это согласуется с данными Husain \& Qureshi (2016), изучавших влияние отношения к порнографии на семейные отношения женщин.

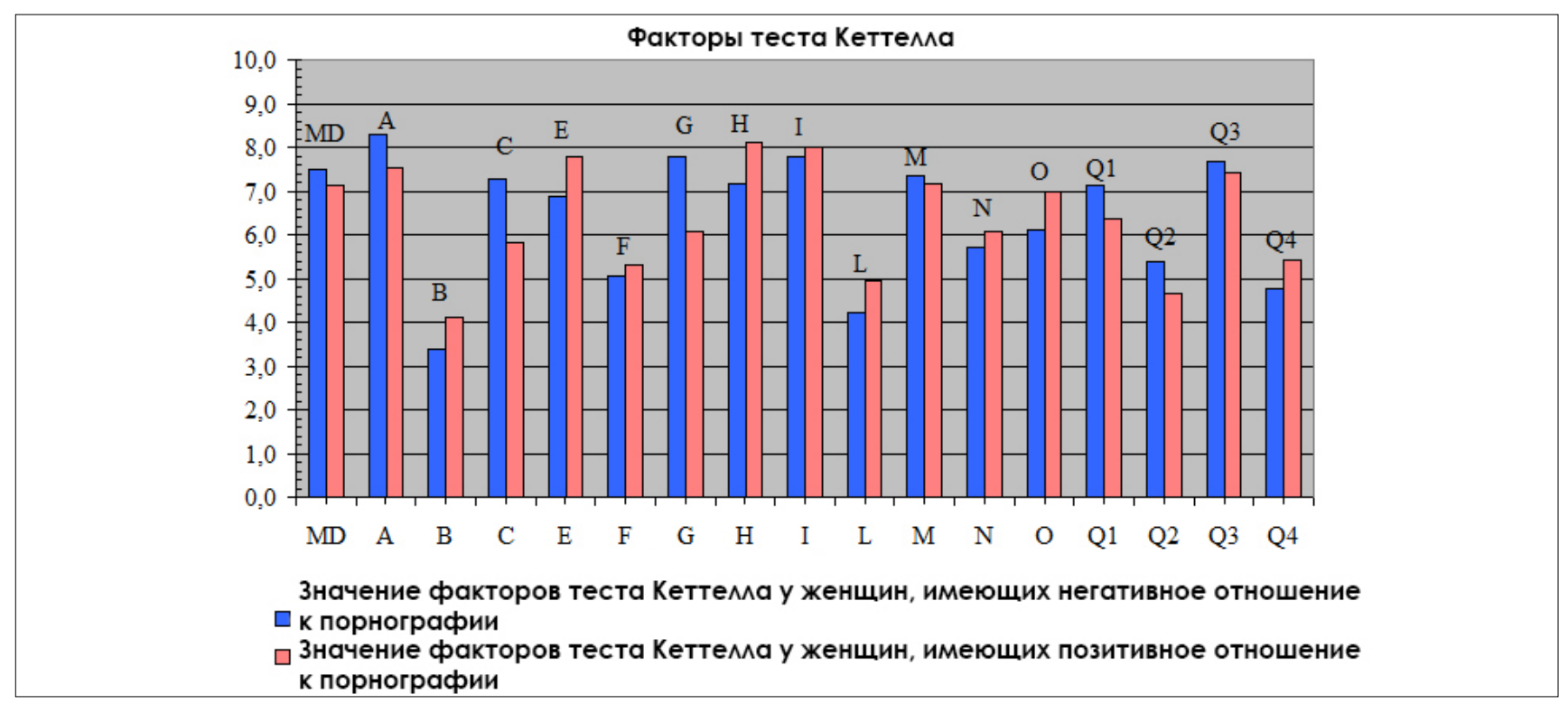

Рисунок 4. Усредненные профили женщин по тесту Кеттел^а с позитивным и негативным отношением к порнографии

Результаты статистической проверки различий представлены в таблице 1. 
ЧЕРНЕЦКАЯ Н. И., ЗЫРЯНОВА И. А., КеДЯРОва Е. А., МОНЖИЕВСКАЯ В. В., УвАРОвА М. Ю.

ЛИЧНОСТНЫЕ ОСОБЕННОСТИ ЖЕНЩИН С НЕГАТИВНЫМИ УСТАНОВКАМИ В СФЕРЕ СЕКСА

РосСИЙСКИЙ пСИХОЛОГИЧЕСКИЙ ЖУРнАл, 2020, Т. 17, № 2, 58-72. doi: 10.21702/rpj.2020.2.4

ОБЩАЯ ПСИХОЛОГИЯ, ПСИХОЛОГИЯ ЛИЧНОСТИ, ИСТОРИЯ ПСИХОЛОГИИ

\begin{tabular}{|c|c|c|c|}
\hline \multicolumn{4}{|c|}{$\begin{array}{l}\text { Таблица } 1 \\
\text { Эмпирические значения критерия } \varphi^{*} \text { Фишера }\end{array}$} \\
\hline$\underline{\text { Фактор }}$ & Обозначение & 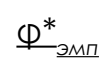 & $\rho$ \\
\hline MD & Алекватная самооценка / неалекватная самооценка & 2,11 & 0,05 \\
\hline A & Замкнутость/общительность & 1,55 & \\
\hline B & $\begin{array}{l}\text { Конкретное (ригиАное) мышление / абстрактное } \\
\text { мышление }\end{array}$ & 2,11 & 0,05 \\
\hline C & $\begin{array}{l}\text { Эмоциональная нестабильность / эмоциональная } \\
\text { стабильность }\end{array}$ & 1,55 & \\
\hline $\mathrm{E}$ & ПоАчиненность/АОминантность & 1,27 & \\
\hline $\mathrm{F}$ & САержанность/экспрессивность & 0,86 & \\
\hline G & $\begin{array}{l}\text { Низкая нормативность поведения / высокая нормативность } \\
\text { поведения }\end{array}$ & 1,88 & 0,05 \\
\hline $\mathbf{H}$ & Робость/смелость & 2,46 & 0,01 \\
\hline I & Жесткость/чувствительность & 0,21 & \\
\hline $\mathbf{L}$ & Аоверчивость (пок^аАистость) / поАОзрительность & 1,89 & 0,05 \\
\hline M & Практичность/мечтательность & 0,14 & \\
\hline $\mathrm{N}$ & Прямолинейность/Аип^оматичность & 0,92 & \\
\hline ○ & Спокойствие/тревожность & 0,49 & \\
\hline Q1 & Консерватизм/радикализм & 0,93 & \\
\hline Q2 & Конорормизм/нонконфрормизм & 0,16 & \\
\hline Q3 & Низкий самоконтроль / высокий самоконтроль & 0,85 & \\
\hline Q4 & Расслабленность/напряженность & 0,84 & \\
\hline
\end{tabular}

На однопроцентном уровне значимости ошибки выявлено, что достоверные различия в профилях женщин с разными установками по отношению к порнографии наблюдаются по фактору Н. На пятипроцентном уровне значимости ошибки выявлено, что достоверные различия в профилях женщин с разными установками по отношению к порнографии наблюдаются по факторам B, G, L и MD. Как указывалось выше, данные факторы отвечают за выраженность в профилях женщин с негативным отношением к порнографии таких признаков, как ригидность мышления, высокая нормативность поведения и самоконтроль, робость (застенчивость), покладистость и высокая самооценка. 
ЧеРНЕЦКАЯ Н. И., ЗЫРЯНОВА И. А., КЕДЯРОва Е. А., МОНЖИЕВСКАЯ В. В., УВАРОвА М. Ю.

ЛИЧНОСТНЫЕ ОСОБЕННОСТИ ЖЕНЩИН С НЕГАТИВНЫМИ УСТАНОВКАМИ В СФЕРЕ СЕКСА

РосСиЙский психологИчЕский жУРнАл, 2020, Т. 17, № 2, 58-72. doi: 10.21702/rpj.2020.2.4

ОБЩАЯ ПСИХОЛОГИЯ, ПСИХОЛОГИЯ ЛИЧНОСТИ, ИСТОРИЯ ПСИХОЛОГИИ

Кроме этого, на пятипроцентном уровне значимости выявлено достоверное отличие женщин с различными установками к порнографии по фактору «фемининность - маскулинность», отвечающему за выраженность в поведении женщины традиционного женского сексуального поведения, соответствующего гендерным стереотипам, описанным в литературе. Это согласуется с низкими баллами по шкалам теста Айзенка «дозволенность», «обезличенный секс», «сексуальная возбудимость» и «сексуальное либидо» и с данными, полученными по тесту Кеттелла о высокой нормативности поведения, самоконтроле, робости (застенчивости) и покладистости.

Нетрудно заметить, что все эти факторы соответствуют качествам добросовестной, ответственной личности, с развитым чувством долга, соблюдающей общепринятые моральные правила и нормы, и в то же время социально пассивной, осторожной, застенчивой, которой трудно принимать новое, особенно в сексуальной сфере в силу некоторой ригидности мышления и стеснительности.

Кроме вышеописанных личностных черт, женщины с негативным отношением к порнографии общительны, эмоционально устойчивы, выдержаны, чувствительны, имеют богатое воображение, проявляют зависимость от мнения и требований группы, нефрустрированы, также как и женщины с позитивным отношением к порнографии.

Анализ распределения факторов теста Кеттелла в усредненных профилях женщин с негативными и позитивными установками к физическому сексуальному контакту (рис. 5) позволяет нам сделать вывод о большей выраженности в профилях женщин, избегающих физического сексуального контакта, таких личностных черт, как подчиненность (E), сдержанность (F), покладистость (терпимость) (L), мечтательность (M). Выявлены более высокие баллы по шкале самооценка (MD), на основании результатов теста Айзенка предполагается соответствие фемининному поведению женщины в вопросах секса.

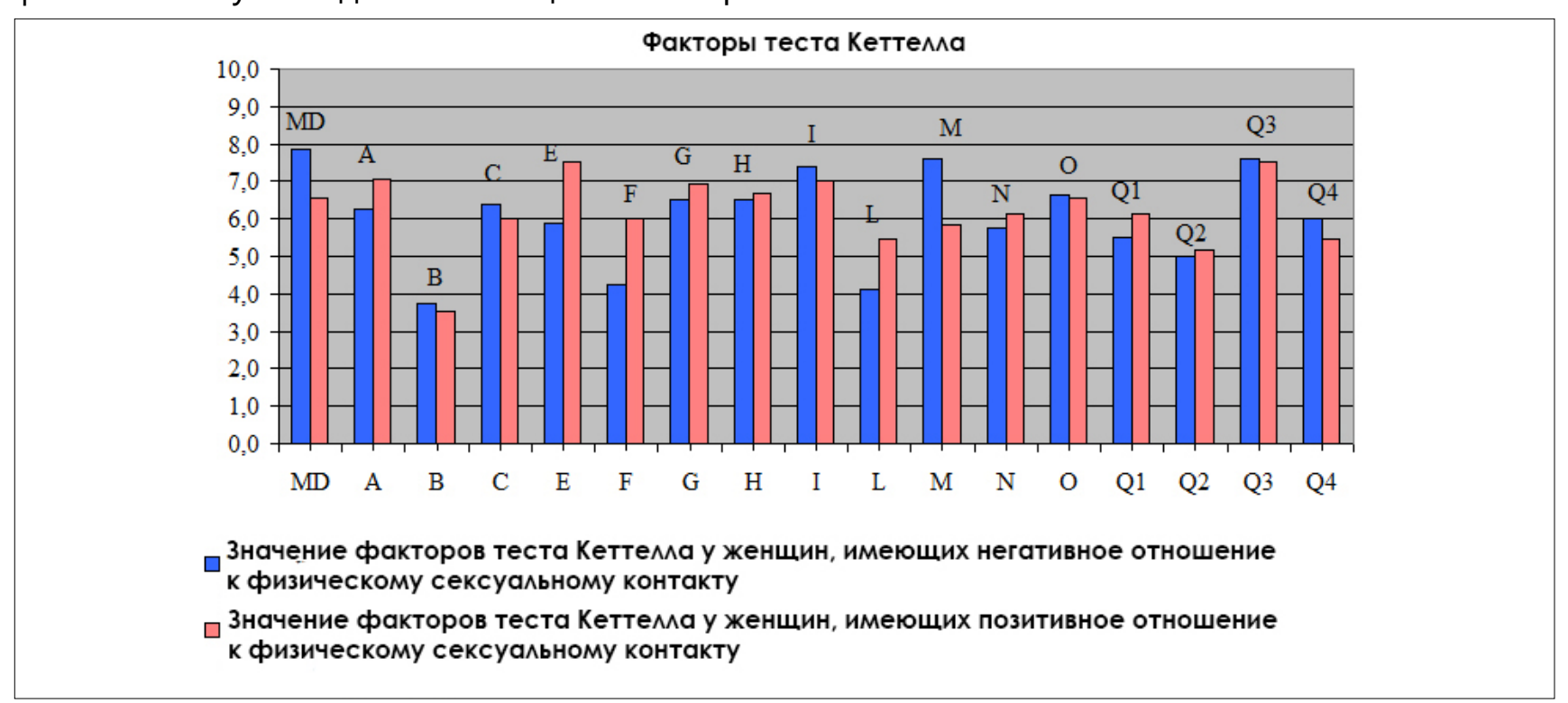

Рисунок 5. Усрелненные профрили женщин по тесту Кеттел^а с позитивным и негативным отношением к фризическому сексуальному контакту 
ЧеРНЕЦКАЯ Н. И., ЗЫРЯНОВА И. А., КЕДЯРОвА Е. А., МОНЖИЕВСКАЯ В. В., УВАРОВА М. Ю.

ЛИЧНОСТНЫЕ ОСОБЕННОСТИ ЖЕНЩИН С НЕГАТИВНЫМИ УСТАНОВКАМИ В СФЕРЕ СЕКСА

РосСИЙСКИЙ пСИХОЛОГИЧЕСКИЙ ЖУРнАл, 2020, Т. 17, № 2, 58-72. doi: 10.21702/rpj.2020.2.4

ОБЩАЯ ПСИХОЛОГИЯ, ПСИХОЛОГИЯ ЛИЧНОСТИ, ИСТОРИЯ ПСИХОЛОГИИ

Результаты статистической проверки для данного аспекта сексуальной сферы представлены в таблице 2.

На однопроцентном уровне значимости ошибки выявлено, что достоверные различия в профилях женщин с разными установками по отношению к физическому сексуальному контакту наблюдаются по факторам $L$ и $\mathrm{M}$. На пятипроцентном уровне значимости ошибки выявлено, что достоверные различия в профилях женщин с разными установками по отношению к физическому сексуальному контакту наблюдаются по факторам E и F. Данные факторы отвечают за выраженность в профилях женщин, избегающих физического секса, таких признаков, как покорность, подчиненность, застенчивость, осторожность, сдержанность в проявлении эмоций, терпимость, покладистость, а также мечтательность, поглощенность своими внутренними иллюзиями.

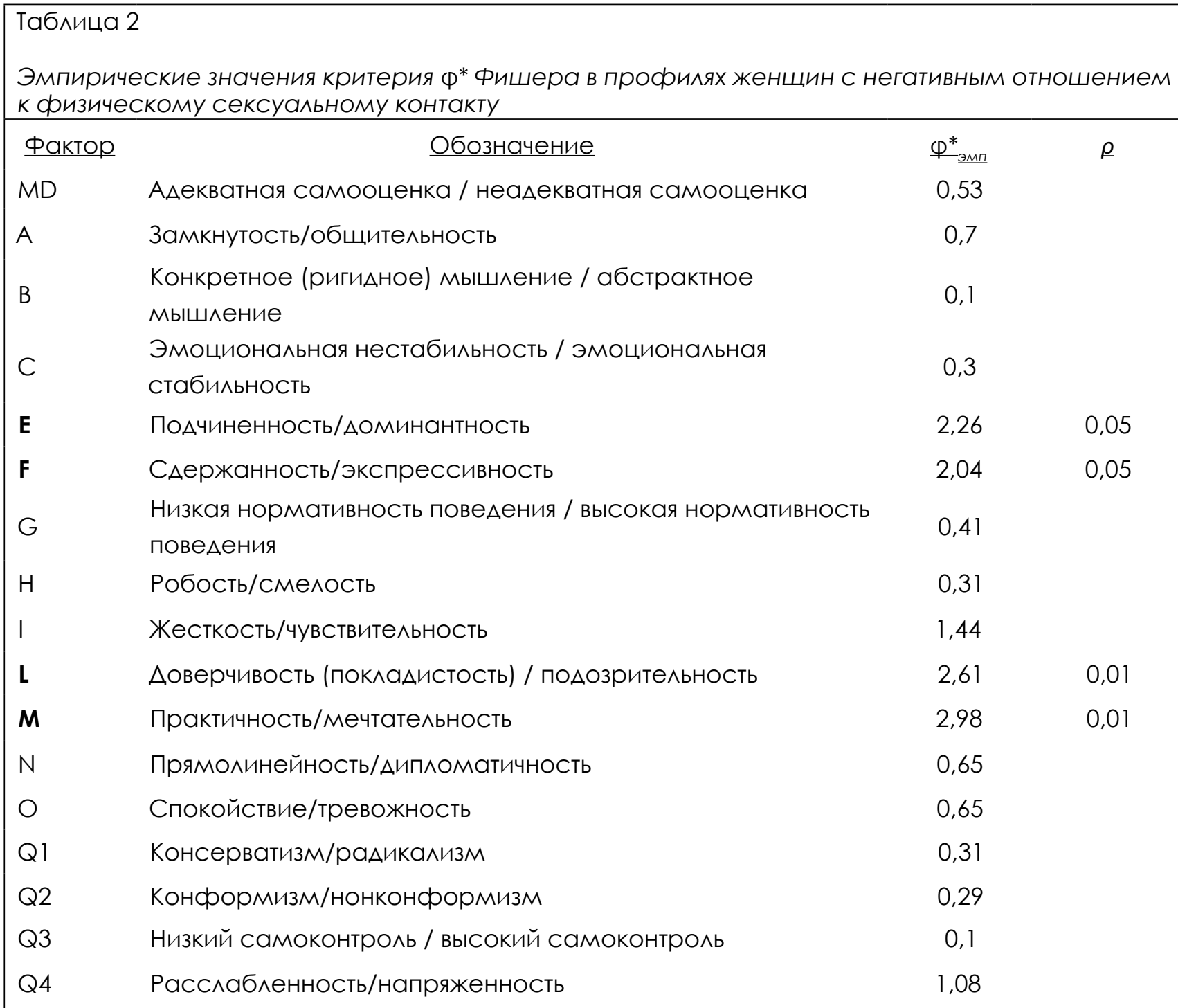


ЧеРНЕЦКАЯ Н. И., ЗЫРЯНОВА И. А., КЕДЯРОва Е. А., МОНЖИЕВСКАЯ В. В., УВАРОвА М. Ю.

ЛИЧНОСТНЫЕ ОСОБЕННОСТИ ЖЕНЩИН С НЕГАТИВНЫМИ УСТАНОВКАМИ В СФЕРЕ СЕКСА

РосСиЙский психологИчЕский жУРнАл, 2020, Т. 17, № 2, 58-72. doi: 10.21702/rpj.2020.2.4

ОБЩАЯ ПСИХОЛОГИЯ, ПСИХОЛОГИЯ ЛИЧНОСТИ, ИСТОРИЯ ПСИХОЛОГИИ

Такие женщины, как правило, «витают в облаках» и ждут своего принца. Приведенные факторы коррелируют между собой и соответствуют качествам мягкой, зависимой, покладистой женщины, готовой отказаться от своих желаний в угоду партнеру, но в глубине души мечтающей о своем единственном и неповторимом мужчине, который будет соответствовать ее внутренним ожиданиям о романтических отношениях. Можно предположить, что женщины с таким личностным портретом незрелы и используют такие психологические защиты, как уход в фантазии, чтобы защитить свой хрупкий внутренний мир.

На пятипроцентном уровне значимости ошибки выявлены достоверные отличия женщин с негативными и позитивными установками к физическому сексуальному контакту по фактору «фемининность - маскулинность». Как указывалось выше, данный фактор отвечает за выраженность в поведении женщины традиционного «женского» сексуального поведения, следования жестким моральным нормам и устоям, что также согласуется с низкими баллами по шкалам теста Айзенка «дозволенность», «обезличенный секс», «сексуальная возбудимость» и «сексуальное либидо» и с данными, полученными по тесту Кеттелла.

Кроме вышеописанных личностных черт, у женщин, избегающих физического сексуального контакта, отмечаются эмоциональная стабильность, ригидность, умение контролировать свои эмоции и поведение. Более низкие оценки по фактору (А) свидетельствуют в пользу трудностей в установлении межличностных, непосредственных контактов, излишней строгости в оценке людей, что может быть связано и с наличием в жизни женщины негативного прошлого опыта, связанного с насилием. Женщины, избегающие физического сексуального контакта, чувствительны, дипломатичны, безмятежны, консервативны, социабельны, нефрустрированы, также как и женщины, стремящиеся к реальному физическому сексу.

Анализ распределения факторов теста Кеттелла в усредненных профилях женщин с негативными и позитивными установками к проявлению сексуальности (рис. 6) свидетельствует о большей выраженности в профилях женщин с отвращением к сексу таких личностных черт, как робость (H), чувствительность (I), покладистость (терпимость) (L), мечтательность (M), тревожность (O), отмечается и более высокая самооценка (MD).

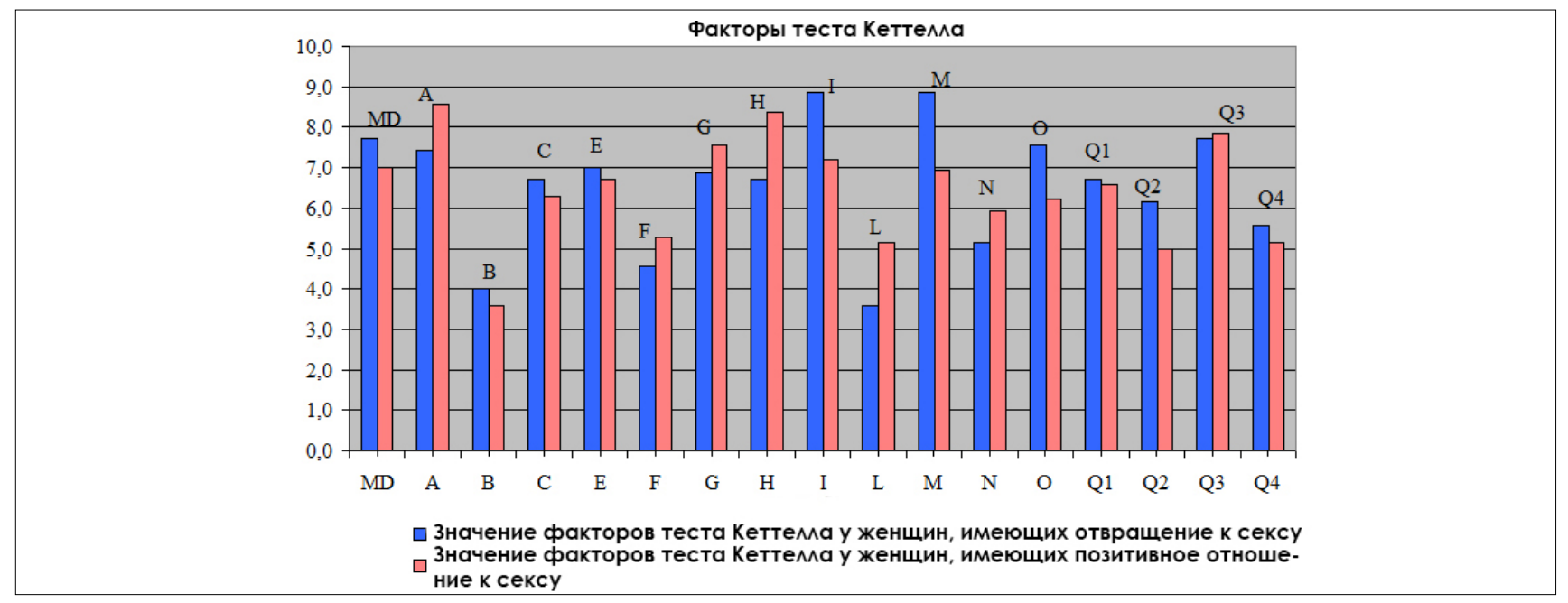

Рисунок 6. Усредненные проорили женщин по тесту Кеттел^а с позитивным и негативным отношением к проявлению сексуальности 
ЧЕРНЕЦКАЯ Н. И., ЗЫРЯНОВА И. А., КеДЯРОва Е. А., МОНЖИЕВСКАЯ В. В., УВАРОвА М. Ю.

ЛИЧНОСТНЫЕ ОСОБЕННОСТИ ЖЕНЩИН С НЕГАТИВНЫМИ УСТАНОВКАМИ В СФЕРЕ СЕКСА

РосСИЙСКИЙ пСИХОЛОГИЧЕСКИЙ ЖУРнАл, 2020, Т. 17, № 2, 58-72. doi: 10.21702/rpj.2020.2.4

ОБЩАЯ ПСИХОЛОГИЯ, ПСИХОЛОГИЯ ЛИЧНОСТИ, ИСТОРИЯ ПСИХОЛОГИИ

Статистические данные для этого параметра представлены в таблице 3.

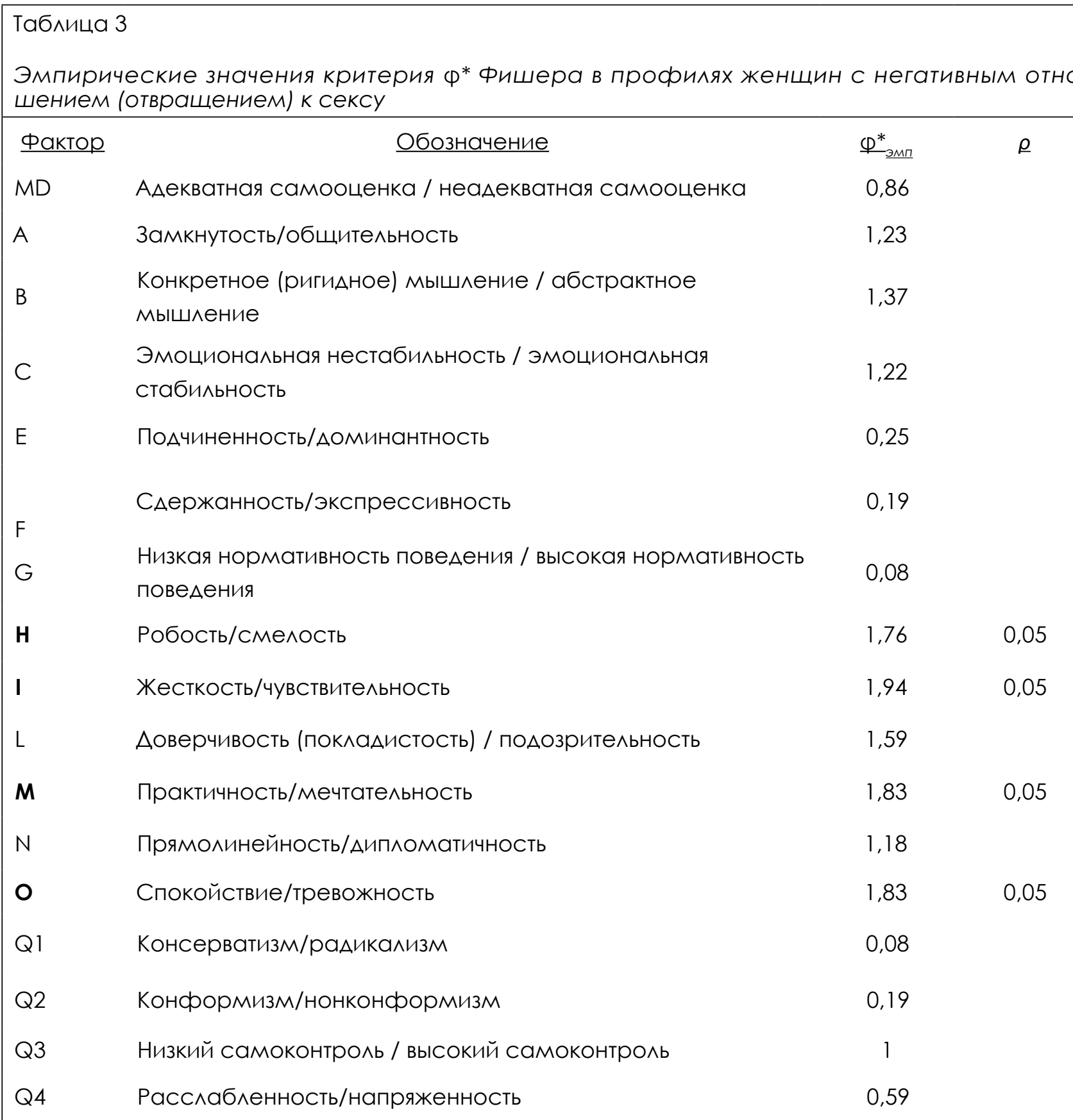

На пятипроцентном уровне значимости ошибки выявлено, что достоверные различия в профилях женщин с разными установками по отношению к сексуальности наблюдаются по факторам $\mathrm{H}, \mathrm{I}, \mathrm{M}, \mathrm{O}$. 
ЧеРНЕЦКАЯ Н. И., ЗЫРЯНОВА И. А., КЕДЯРОва Е. А., МОНЖИЕВСКАЯ В. В., УВАРОвА М. Ю.

ЛИЧНОСТНЫЕ ОСОБЕННОСТИ ЖЕНЩИН С НЕГАТИВНЫМИ УСТАНОВКАМИ В СФЕРЕ СЕКСА

РосСиЙский психологИчЕский жУРнАл, 2020, Т. 17, № 2, 58-72. doi: 10.21702/rpj.2020.2.4

ОБЩАЯ ПСИХОЛОГИЯ, ПСИХОЛОГИЯ ЛИЧНОСТИ, ИСТОРИЯ ПСИХОЛОГИИ

Как описано выше, указанные факторы отвечают за выраженность в профилях женщин таких признаков, как робость, застенчивость, эмоциональная сдержанность, повышенная чувствительность, склонность к романтизму, мечтательность, ориентированность на свой внутренний мир, беспокойство, ранимость, склонность к депрессиям; могут наблюдаться чувство вины и недовольство собой. Можно предположить, что женщины с таким личностным портретом слишком чувствительны, боязливы, чувствуют себя неуверенно в общении с другими людьми, им трудно устанавливать контакты, тем более в партнерских отношениях, из-за утонченной эмоциональности и, возможно, невротизации (высокий балл по шкале I). Из-за чувства уязвимости и завышенных притязаний к партнеру они избегают сексуальных отношений как наиболее травмирующих их внутренний мир, что коррелирует с низкими баллами по шкале $\mathrm{F}$, предполагающей осторожность в выборе партнера по общению. Можно предположить и более высокий культурный уровень, художественный тип личности и тревожность как свойство личности у женщин исследуемой группы. Приведенные выводы согласуются с более высоким уровнем значений по шкале «сексуальная невротичность» теста Айзенка, что может указывать на некоторую разбалансированность или функциональные сдвиги в поведении женщин, имеющих отвращение к сексу. Выявленные низкие значения по шкале «сексуальная возбудимость» указывают на необходимость в целом ряде определенных условий, чтобы прийти в состояние сексуального возбуждения, что подчеркивается высокой эмоциональностью и чувствительностью женщин данной группы. Все вышесказанное может быть связано и с наличием в жизни женщины негативного прошлого опыта, связанного с насилием, как и у женщин, избегающих физического сексуального контакта.

В личностных профилях женщин с негативными установками к проявлению сексуальности отмечаются высокие оценки по шкалам эмоциональной стабильности (C), нормативности поведения (G) и самоконтроля (Q3), что определяет выраженность волевых характеристик личности, как и в профилях женщин с негативным отношением к порнографии.

Достоверных отличий женщин с отвращением к сексу по фактору «фемининность - маскулинность» от женщин с позитивными установками к сексу на основании расчетов нами не выявлено.

Несмотря на ряд существенных отличий, женщины с негативным отношением к проявлению сексуальности общительны, самостоятельны, им свойственна независимость суждений, взглядов и поведения, также как и женщинам с позитивным отношением к сексу.

\section{Обсуждение результатов}

Таким образом, нами выявлено, что среди женщин с негативными установками в сфере секса преобладают традиционные (фемининные) взгляды на сексуальное поведение, стремление к установлению личных отношений между партнерами, сохранению брачных уз, а также нетерпимое отношение ко всему «аморальному» и «постыдному». Как правило, они имеют низкую сексуальную чувствительность и возбудимость.

В личностных профилях женщин с негативными установками в сфере секса преобладают такие личностные черты, как высокая, порой неадекватная самооценка, ригидность мышления, высокая нормативность поведения, подчиненность, застенчивость, осторожность в выборе партнера, сдержанность в проявлении эмоций, а также мечтательность, поглощенность своими внутренними иллюзиями.

Для женщин с крайне негативным отношением к сексу, наряду с указанными выше личностными особенностями, выделяются повышенная чувствительность, склонность к романтизму, 
ЧеРНЕЦКАЯ Н. И., ЗЫРЯНОВА И. А., КЕДЯРОвА Е. А., МОНЖИЕВСКАЯ В. В., УВАРОВА М. Ю.

ЛИЧНОСТНЫЕ ОСОБЕННОСТИ ЖЕНЩИН С НЕГАТИВНЫМИ УСТАНОВКАМИ В СФЕРЕ СЕКСА

РосСИЙСКИЙ пСИХОЛОГИЧЕСКИЙ ЖУРнАл, 2020, Т. 17, № 2, 58-72. doi: 10.21702/rpj.2020.2.4

ОБЩАЯ ПСИХОЛОГИЯ, ПСИХОЛОГИЯ ЛИЧНОСТИ, ИСТОРИЯ ПСИХОЛОГИИ

беспокойство, ранимость, склонность к депрессиям; могут наблюдаться чувство вины и недовольство собой и тревожность как свойство личности.

Полученные результаты подтверждают основную гипотезу о том, что женщины с негативными установками в сфере секса имеют специфические личностные особенности.

Полученные теоретические и практические данные могут быть использованы в консультативной практике, где на основании выявленных личностных особенностей женщин можно предполагать наличие негативных установок в сфере секса и разрабатывать соответствующие коррекционные программы, а также в практике воспитания и психологического сопровождения девушек-подростков, нивелируя факторы, способствующие формированию негативных установок в сфере секса.

\section{Литература}

Айзенк, Г. Ю. и Вильсон, Г. (2000). Как измерить личность (А. Белопольский, пер. с англ.). Москва: Когито-Центр.

Голод, С. И. (1996). ХХ век и тенденции сексуальных отношений в России. Санкт-Петербург: Алетейя.

Гусакова, Т. Ф. (2010). Восприятие гедонистической доктрины в России: пути и проблемы. Вестник Тюменского государственного университета, 5, 181-186.

Дерягин, Г. Б. (н. д.). Синдромы сексуальных расстройств, сексуальные комплексы и мифы в культурах мира. Доступ 18 февраля 2020, источник http://sudmed-nsmu.narod.ru/articles/ sexcompl.html

Дерягин, Г. Б., Сидоров, П. И. и Соловьев, А. Г. (2003). Психосоциальные предпосылки сексуально виктимного и криминогенного поведения молодёжи. Сексология и сексопатология, 6, 30-37.

Ильин, Е. П. (2007). Дифференциальная психофизиология мужчины и женщины. СанктПетербург: Питер.

Кришталь, В. В. (н. д.). О причинах и условиях нарушения сексуального здоровья у женщин. Доступ 18 февраля 2020, источник https://www.docsity.com/ru/o-prichinah-i-usloviyah -narusheniya-seksualnogo-zdorovya-u-zhenshchin/1355936/

Маркова, М. В. (н. д.). Психологчческие особенности личности супругов с сексуальной дисгармонией при дисциркуляторной гипертонической энцефалопатии у жены. Доступ 18 февраля 2020, источник https://mirznanii.com/a/210723/psikhologicheskie -osobennosti-lichnosti-suprugov-s-seksualnoy-disgarmoniey/

Нашхоев, М. Р. и Ильина, С. В. (2000). Психологические особенности женщин, занимающихся уличным секс-бизнесом. Инфекции, передаваемые половым путем, 6, 31-36.

Нохуров, А. (1988). Нарушения сексуального поведения. Москва: Медицина.

Попова, Ю. А. (2006). Психогенная аноргазмия у женщин: психофизиологический, личностный и интерперсональный аспекты. Медицинская консультация, 2, 4-7.

Рукавишников, А. А. и Соколова, М. В. (2002). Факторный личностный опросник Р. Кеттелла: методическое руководство. Санкт-Петербург: Иматон.

Темкина, А. (2002). Сценарии сексуальности и сексуальное удовольствие в женских биографиях. В Е. Здравомыслова, А. Темкина (ред.), В поисках сексуальности (с. 89-139). СанктПетербург: Дмитрий Буланин.

Чалова, А. В. (2015). Особенности женской сексуальности в контексте межличностных отношений. Вестник ТвГУ. Серия «Педагогика и психология», 2, 210-216. 
ЧЕРНЕЦКАЯ Н. И., ЗЫРЯНОва И. А., КеДЯРОва Е. А., МОНЖИЕВСКАЯ В. В., УВАРОВА М. Ю.

ЛИЧНОСТНЫЕ ОСОБЕННОСТИ ЖЕНЩИН С НЕГАТИВНЫМИ УСТАНОВКАМИ В СФЕРЕ СЕКСА

РосСиЙский психологИчЕский жУРнАл, 2020, Т. 17, № 2, 58-72. doi: 10.21702/rpj.2020.2.4

ОБЩАЯ ПСИХОЛОГИЯ, ПСИхОЛОГИЯ лИЧнОстИ, ИСТОРИя ПСИхОЛОГИИ

Чалова, А. В. (2016). Взаимосвязь социально-психологической и сексуально-поведенческой адаптации с особенностями сексуальной удовлетворенности у женщин в устойчивых супружеских парах. Новая наука: опыт, традиции, инновации, 591-2, 157-159.

Amaro, H. (1995). Love, sex, and power: Considering women's realities in HIV prevention. American Psychologist, 50(6), 437-447. doi: 10.1037//0003-066X.50.6.437

Bass, T. M. (2016). Exploring female sexuality: Embracing the whole narrative. North Carolina Medical Journal, 77(6), 430-432. doi: 10.18043/ncm.77.6.430

Ellis, H. (2010). Studies in the psychology of sex. Nabu Press.

Fisher, W. A., White, L. A., Byrne, D., \& Kelley, K. (1988). Erotophobia-erotophilia as a dimension of personality. The Journal of Sex Research, 25(1), 123-151. doi: $10.1080 / 00224498809551448$

García-Vega, E., Rico, R., \& Fernández, P. (2017). Sex, gender roles and sexual attitudes in university students. Psicothema, 29(2), 178-183. doi: 10.7334/psicothema2015.338

Geer, J. H., \& Robertson, G. G. (2005). Implicit attitudes in sexuality: Gender differences. Archives of Sexual Behavior, 34, 671-677. doi: 10.1007/s10508-005-7923-8

Hsu, B., Kling, A., Kessler, C., Knapke, K., Diefenbach, P., \& Elias, J. E. (1994). Gender differences in sexual fantasy and behavior in a college population: A ten-year replication. Journal of Sex \& Marital Therapy, 20(2), 103-118. doi: 10.1080/00926239408403421

Husain, W., \& Qureshi, Z. (2016). Preferences in marital sexual practices and the role of pornography. Sexologies, 25(2), e35-e41. doi: 10.1016/j.sexol.2016.01.005

Kinsey, A. C., Pomeroy, W. B., Martin, C. E., \& Gebhard, P. H. (1998). Sexual behavior in the human female. Indiana University Press.

Meston, C. M., \& Ahorld, T. (2010). Ethnic, gender, and acculturation influences on sexual behaviors. Archives of Sexual Behaviour, 39, 179-189. doi: 10.1007/s10508-008-9415-0

Peplau, L. A. (2003). Human sexuality: How do men and women differ? Current Directions in Psychological Science, 12(2), 37-40. doi: 10.1111/1467-8721.01221

Petersen, J. L., \& Hyde, J. S. (2010). A meta-analytic review of research on gender differences in sexuality, 1993-2007. Psychological Bulletin, 136(1), 21-38. doi: $10.1037 / a 0017504$

Rammsayer, T. H., Borter, N., \& Troche, S. J. (2017). The effects of sex and gender-role characteristics on facets of sociosexuality in heterosexual young adults. The Journal of Sex Research, 54(2), 254-263. doi: 10.1080/00224499.2016.1236903

Renshaw, D. C. (2001). Women coping with a partner's sexual avoidance. The Family Journal, 9(1), 11-16. doi: 10.1177/1066480701091004

Sathyanarana Rao, T. S., \& Nagaraj, A. M. (2015). Female sexuality. Indian Journal of Psychiatry, 57(6), 296-302. doi: 10.4103/0019-5545.161496

Конфликт интересов отсутствует 